\title{
Use of DNA haplotype analysis in diagnosis of familial hypercholesterolaemia in 31 German families
}

\author{
H Schuster, G Rauh, Ch Gerl, Ch Keller, G Wolfram, N Zöllner
}

\begin{abstract}
In the majority of patients, familial hypercholesterolaemia (FH) is caused by different mutations affecting the well defined low density lipoprotein receptor (LDLR) gene. However, $3 \%$ of patients in Munich with a clinical diagnosis of FH have a particular mutation in the apolipoprotein $B$ gene causing familial defective apolipoprotein B-100 (FDB). To date none of the LDLR mutations causing FH in German patients has been identified and it is therefore not yet possible to use DNA technology for direct diagnosis. However, indirect molecular diagnosis based on genetic linkage of common restriction fragment length polymorphisms (RFLPs) of the LDLR gene can be used for diagnosis in family studies. Patients with FDB were excluded from this study. Genotypes and haplotypes of four RFLPs (StuI, Apall 5', PvulI, and NcoI) were determined in a total of 164 independent alleles from 31 pedigrees that included 222 subjects. Allele frequencies and four RFLP haplotype distribution did not differ significantly from those reported in other populations. The applicability of DNA diagnosis in our lipid clinic is comparable with the estimation from calculations on frequencies and heterozygosities of RFLPs, as predicted using these four RFLPs before. On the basis of cosegregation of haplotypes and normo- or hypercholesterolaemia in one or more sibs or offspring, defective and normal LDLR gene alleles could be distinguished in 42 of 58 heterozygous FH patients who were heterozygous for at least one RFLP. In 97 of
\end{abstract}

Medizinische Poliklinik der Universität München, Pettenkoferstrasse 8a, D-8000 München 2, Germany. H Schuster, G Rauh, Ch Gerl, Ch Keller, G Wolfram, N Zöllner

Correspondence to Dr Schuster.

Received for publication 1 November 1990.

Revised version accepted for publication 14 May 1991.
$134(72 \%)$ children of these 42 subjects, diagnosis of FH could be carried out unambiguously. Cholesterol levels of subjects with normal and defective LDLR genes show significant overlap, especially in younger cases, and FH was diagnosed in 10 cases with normal cholesterol levels and excluded in five cases with slightly raised cholesterol levels.

Familial hypercholesterolaemia $(\mathrm{FH})$ is a common inherited disease characterised clinically by raised concentrations of low density lipoprotein (LDL) cholesterol levels in the blood, tendon xanthomata, an increased risk of myocardial infarction, and genetically by autosomal dominant inheritance. ${ }^{1}$ Brown, Goldstein, and coworkers have shown over the last few years that $\mathrm{FH}$ results from different genetic defects in a cell surface receptor that normally controls the removal of LDL from plasma. ${ }^{1-3}$ Some populations, like the Afrikaners in South Africa, ${ }^{4}$ the French Canadians, ${ }^{5}$ and the Finnish, ${ }^{6}$ carry only a few mutations. In these cases, direct molecular diagnosis using appropriate DNA technology is possible if the specific LDLR defect is known. No mutation has yet been identified in the German population. We have previously shown, using four RFLPs of the LDLR gene, that there are eight different haplotypes carrying defective alleles of the gene in a sample of $\mathrm{FH}$ patients from Munich. ${ }^{7}$ This suggests at least eight different mutations must be present and because of the mutational heterogeneity only indirect molecular diagnosis of $\mathrm{FH}$ is possible based on genetic linkage analysis of common DNA polymorphisms of the LDLR gene in family studies.

Today, at least 10 RFLPs of the human LDLR gene are known. ${ }^{8}$ For some of these RFLPs the allele frequencies are too low to be used for linkage analysis, and linkage disequilibrium among RFLPs reduces their informativeness in pedigree analysis. Recently, a strategy for haplotype analysis of the LDLR gene was suggested in a Caucasian American sample, which identified the RFLPs that were most useful. ${ }^{9}$

We have used four RFLPs (StuI, ApalI 5', PvuII, and $\mathrm{NcoI}$ ) to carry out diagnosis of $\mathrm{FH}$ in families 
attending a lipid clinic. Allele frequencies and haplotype data were compared with data reported from other populations. The number of informative subjects for these four RFLPs was compared with predictive data based on pairwise polymorphism information content (PIC) values ${ }^{10}$ and index of heterozygosity calculated on genotype and haplotype distribution. Cholesterol levels of subjects with normal and defective LDLRs were also compared.

\section{Patients and methods}

\section{PATIENTS}

We have investigated 222 subjects from 31 German families attending a lipid clinic in Munich, in which at least five family members were available for family studies. In these families, 58 subjects had 134 children in whom diagnosis should be carried out by recombinant DNA techniques. In 21 of these families $\mathrm{FH}$ was confirmed by skin fibroblast studies as described previously. ${ }^{11}$

Blood samples were taken 12 hours after the last meal. Cholesterol levels were determined after a period without drug treatment of at least six weeks or when the patients came to the lipid clinic for the first time and before therapy. HDL cholesterol was determined by a precipitation method and LDL cholesterol was estimated by the formula of Friedewald $e t a l^{12}$ if triglycerides were below $200 \mathrm{mg} / \mathrm{dl}$. Lipoproteins were measured by preparative ultracentrifugation, according to Havel et $a l,{ }^{13}$ in all other cases.

PROBES FOR THE LDL RECEPTOR GENE

The gene probe used was pLDLR-2HH1, a kind gift of Dr D W Russell, Dallas, USA. The plasmid contains a $1.9 \mathrm{~kb}$ fragment of the full length cDNA which hybridises with exon 11 to exon 18 of the gene. The fragment was excised from a $1 \%$ low gelling temperature agarose gel and labelled by means of a random oligonucleotide primer with ${ }^{32} \mathrm{P}-\mathrm{dCTP}$ at $3000 \mathrm{Ci} / \mathrm{mmol}$, as described previously. $^{?}$

\section{DNA ANALYSIS}

Total genomic DNA was extracted from white blood cells using a triton X-100 lysis method. ${ }^{14} \mathrm{~A}$ total of $5 \mu \mathrm{g}$ of high molecular weight genomic DNA was digested with the restriction enzymes ApalI and BamHI, NcoI, PvuII, and StuI (Amersham International) using conditions recommended by the manufacturer. The fragments were separated by electrophoresis on $\mathbf{0 . 8 \%}$ agarose gels. After electrophoresis, the DNA was transferred from the gel to nylon membranes (Hybond $\mathbf{N}$, Amersham International) and fixed with UV light radiation. The membranes hybridised with the radioactive LDLR gene probe in $7 \%$ sodium dodecyl sulphate (SDS) and $0.5 \mathrm{~mol} / 1$ phosphate buffer $(\mathrm{pH} \mathrm{7.0})$ at $65^{\circ} \mathrm{C}$ using a rotation oven (Bachhofer, West Germany) for 24 hours. Filters were washed finally in $1 \times$ SSC ( $150 \mathrm{mmol} / 1 \mathrm{NaCl}, 15 \mathrm{mmol} / 1$ sodium citrate), $0.1 \%$ SDS and exposed to $x$ ray film (Kodak X-Omat AR) for one to three days. Familial defective apo B-100 (FDB) owing to the 3500 mutation was excluded in all index cases using allele specific oligomelting, as described previously. ${ }^{15}$

\section{Results}

A total of 222 subjects was genotyped for the StuI, ApalI 5', PvuII, and NcoI RFLPs. Allele frequencies were determined by gene counting. For the unrelated subjects, the genotype distribution for all RFLPs was not significantly different from the expected value if the population is in HardyWeinberg equilibrium (data not shown).

The frequencies and polymorphism of these four RFLPs were determined among 164 independent LDLR gene alleles (table 1). To assess diagnosis with these RFLPs in our population, the number of heterozygous subjects was compared with a standardised estimate by calculating the PIC values for the polymorphisms. ${ }^{10}$ The index of heterozygosity for StuI, ApalI 5', and NcoI was slightly higher than expected from PIC values, whereas the index of heterozygosity for PvuII was slightly lower. Table 2 shows the cumulative heterozygosity of the four RFLPs. For ApalI 5', 50\% of our probands were heterozygous and therefore informative for DNA diagnosis. With the additional use of NcoI, the heterozygosity index increases to a cumulative value

Table 1 Frequencies and PIC values of four RFLPs at the LDLR gene locus among 164 independent chromosomes. compared to heterozygosity in 58 heterozygous FH patients.

\begin{tabular}{lccc}
\hline RFLP & $\begin{array}{c}\text { Frequency } \\
\text { of }+ \text { site }\end{array}$ & PIC value & Heterozygosity \\
\hline StuI & 0.911 & 0.095 & $0.138(\mathrm{n}=8 / 58)$ \\
ApalI 5' & 0.472 & 0.374 & $0.500(\mathrm{n}=29 / 58)$ \\
PvuII & 0.350 & 0.352 & $0.345(\mathrm{n}=20 / 58)$ \\
NcoI & 0.706 & 0.329 & $0.483(\mathrm{n}=28 / 58)$ \\
\hline
\end{tabular}

Table 2 Cumulative heterozygosity of four RFLPs at the LDLR gene locus among 58 heterozygous $F H$ patients.

\begin{tabular}{lcc}
\hline RFLP & Location of site & $\begin{array}{c}\text { Cumulative } \\
\text { heterozygosity }\end{array}$ \\
\hline ApalI 5' & Intron 15 & $0 \cdot 500(\mathrm{n}=29 / 58)$ \\
NcoI & Exon 18 & $0 \cdot 672(\mathrm{n}=39 / 58)$ \\
PvuII & Intron 15 & $0 \cdot 672(\mathrm{n}=39 / 58)$ \\
StuI & Exon 8 & $0 \cdot 724(\mathrm{n}=42 / 58)$ \\
\hline
\end{tabular}


of 0.67 . As predicted by calculation of linkage disequilibrium with $\mathrm{NcoI} \mathrm{I}^{916}$ the addition of the PvuII genotype gives no further information. The inclusion of StuI slightly increases the index of heterozygosity to $72 \%$. In conclusion, the ApalI $5^{\prime}$ and $N c o I$ RFLPs are the most informative and should be chosen first for family studies. The additional use of PvuII and StuI is of limited value because of high linkage disequilibrium and low allele frequency, respectively.

DNA haplotypes for all subjects were constructed by segregation analysis based on the assumption that there has been no recombination events within these families. Haplotypes of 131 normal and 33 defective independent LDLR gene alleles are shown in table 3. In comparison with data from a Caucasian American population ${ }^{9}$ and a group of patients from South Africa, ${ }^{16}$ there was no significant difference in haplotype distribution in normal subjects. In the Afrikaner population a well defined founder effect causes a significant difference in haplotype distribution between the normal population and $\mathrm{FH}$ subjects. ${ }^{4}$ Haplotype distribution was not significantly different between normal and defective alleles in the Munich population, but haplotype 3 is more common in the FH group. This haplotype may therefore carry the most frequent mutant allele in the Munich population.

In the 31 pedigrees, there were 58 parents who had a diagnosis of $\mathrm{FH}$ based on plasma cholesterol levels above the 95th centile for age and gender. In 42 of these 58 subjects the defective and normal alleles of the LDLR gene could be distinguished on the basis of cosegregation between haplotypes and normo- or hypercholesterolaemia in one or more sibs or offspring. To illustrate how genetic diagnosis of FH was carried out using haplotype analysis, a representative family pedigree is shown in fig $1 \mathrm{~A}$ in which the haplotype $11^{*}$ of the proband cosegregates with hypercholesterolaemia. Therefore, the defective allele can be identified as $11^{*}$ in this particular pedigree. Fig $1 B$ shows another family in which the allele $8^{*}$ cosegregates with hypercholesterolaemia. However, in this family the proband has inherited the defective allele but does not show the FH phenotype. In 97 of 133 children confirmation of the genetic diagnosis of FH could be carried out. In 60 cases the child had inherited the allele of the LDLR gene confirmed to be defective in the kindred and in 37 cases the normal allele had been inherited (fig 2). Table 4 shows the lipid levels of both groups. There was a significant difference $(p<0.001)$ in mean cholesterol and LDL cholesterol between the groups using standard analysis of variance, but there was overlap in LDL cholesterol levels between the groups. Fig 3 shows age and sex dependent total cholesterol levels of family members with defective and normal LDLR genes. In 10 cases (three females, seven males), diagnosis of $\mathrm{FH}$ was confirmed based on inheritance of the defective allele in the kindred although cholesterol levels were below the 95th centile for this sample..$^{18}$ In five cases (three females, two males), the defective allele in the kindred had not been inherited and a genetic diagnosis of $\mathrm{FH}$ was excluded, although cholesterol levels were above the 95th centile.

Table 3 Haplotype distribution of 131 normal and 33 defective independent LDL receptor genes for four RFLPs from 31 families including 222 subjects from a German population in comparison to other populations. ( + ) denotes the presence of the variable restriction site and (-) the absence of the site. Difference in haplotype distribution is not significant in the German population. Data for Caucasian Americans reported by Leitersdorf et al 9 and for white Afrikaners by Kotze et al. ${ }^{16}$

\begin{tabular}{|c|c|c|c|c|c|c|c|c|c|c|c|c|c|c|}
\hline \multirow[b]{3}{*}{ Haplotype } & \multirow[b]{3}{*}{ StuI } & \multirow[b]{3}{*}{ ApallI } & \multirow[b]{3}{*}{ PvuI } & \multirow[b]{3}{*}{ Ncol } & \multicolumn{4}{|c|}{ Germany } & \multirow{2}{*}{\multicolumn{2}{|c|}{$\frac{\text { USA }}{\text { Normal }}$}} & \multicolumn{4}{|c|}{ South Africa } \\
\hline & & & & & \multicolumn{2}{|c|}{ Normal } & \multicolumn{2}{|c|}{ FH } & & & \multicolumn{2}{|c|}{ Normal } & \multicolumn{2}{|c|}{ FH } \\
\hline & & & & & No & $\%$ & No & $\%$ & No & $\%$ & No & $\%$ & No & $\%$ \\
\hline $\begin{array}{l}1 \\
2\end{array}$ & $\begin{array}{l}+ \\
+\end{array}$ & $\begin{array}{l}+ \\
+\end{array}$ & $\begin{array}{l}+ \\
+\end{array}$ & + & 3 & $2 \cdot 3$ & & & 1 & 0.8 & 1 & 0.9 & & \\
\hline 3 & + & + & - & + & 35 & 26.5 & 17 & $51 \cdot 7$ & 59 & $48 \cdot 0$ & 39 & $35 \cdot 2$ & 2 & $2 \cdot 0$ \\
\hline 4 & + & + & - & - & 10 & 7.6 & & & 3 & 2.4 & 6 & 5.4 & 2 & 2.0 \\
\hline 6 & + & - & + & - & 1 & 0.8 & & & 1 & 0.8 & & & & \\
\hline 7 & + & - & - & + & 8 & $6 \cdot 1$ & 2 & 6.0 & 2 & 1.6 & 2 & $1 \cdot 8$ & 85 & 85.9 \\
\hline 8 & + & - & - & - & 33 & $25 \cdot 2$ & 5 & $15 \cdot 1$ & 30 & $24 \cdot 4$ & 31 & 27.9 & & \\
\hline 9 & - & + & + & + & & & & & & & & & & \\
\hline 10 & - & + & + & - & 1 & 0.8 & & & & & & & & \\
\hline 11 & - & + & - & + & 1 & 0.8 & 1 & 3.0 & & & & & & \\
\hline 12 & - & + & - & - & 1 & 0.8 & & & & & & & & \\
\hline 13 & - & - & + & + & 7 & $5 \cdot 3$ & & & 7 & $5 \cdot 7$ & 6 & $5 \cdot 4$ & 10 & $10 \cdot 1$ \\
\hline 14 & - & - & + & - & 1 & 0.8 & & & & & & & & \\
\hline 16 & - & - & - & - & 1 & 0.8 & & & & & & & & \\
\hline Total & & & & & 131 & & 33 & & 123 & & 111 & & 99 & \\
\hline
\end{tabular}




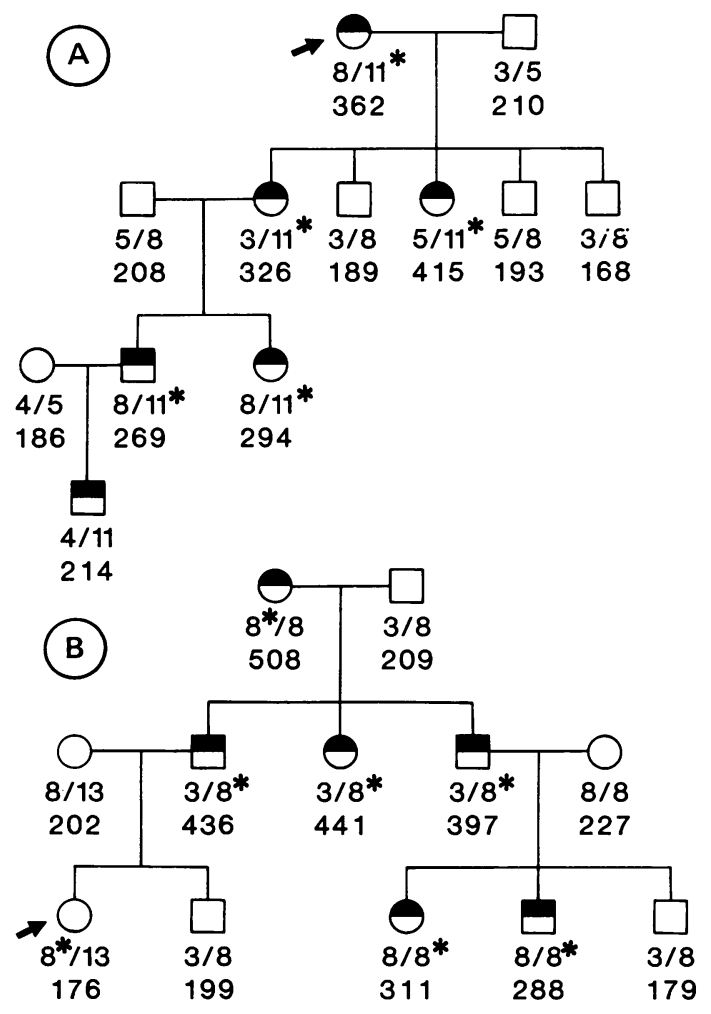

Figure 1 Pedigrees of two representative $F H$ families. The arrow indicates the proband. Total serum cholesterol levels are given in $\mathrm{mg} / \mathrm{dl}$. Hypercholesterolaemia above the 95th centile for age and gender ${ }^{18}$ is shown by shaded symbols. The genotypes of four RFLP haplotypes are outlined according to table 3. (A) Family 1454. The allele $11^{*}$ characterised by its four RFLP haplotype cosegregates with the FH phenotype. (B) Family 1317. The allele $8^{*}$ cosegregates with the FH phenotype. However, in this family the proband aged 6 has inherited the defective allele and exhibits cholesterol levels below the 95th centile for age and gender.

\section{Discussion}

The aim of this study was to determine the applicability of DNA diagnosis with RFLPs of the LDLR gene in 31 German FH families. Since the cloning of the human LDLR gene by Brown, Goldstein, and coworkers, FH can be diagnosed by recombinant DNA technology either using restriction enzyme mapping to detect major rearrangements of the gene or using RFLPs and linkage analysis in family studies. To date, at least 20 deletions or insertions have been mapped with restriction enzyme digests. These defects concern all four classes of mutations that were already known before cloning of the LDLR gene and disrupt the synthesis, intracellular transport, binding, and internalisation function of

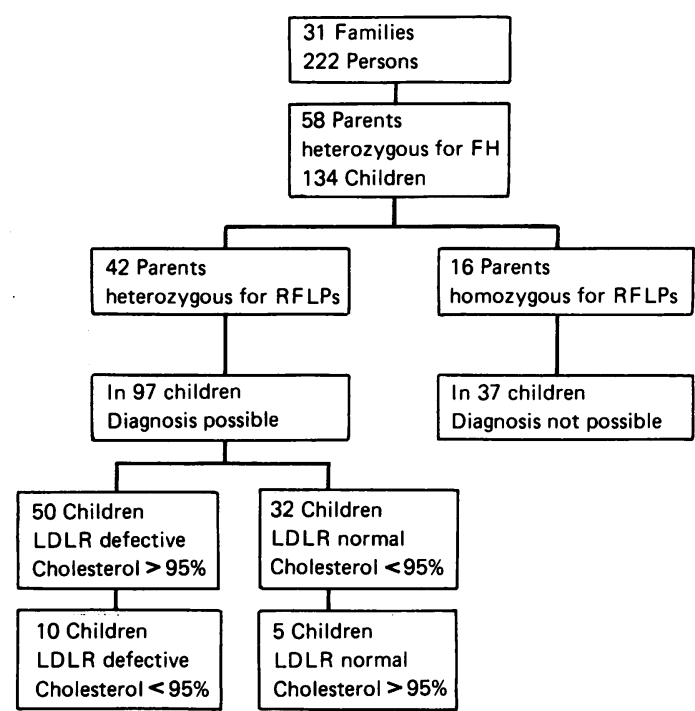

Figure 2 Flow chart showing the applicability of DNA diagnosis in FH using haplotype analysis in the LDLR gene in 31 German families.

the LDLR gene. In most populations, major rearrangements account for only a small number of defects. However, two deletions have been found that are most common in two different populations. In a French-Canadian population a $10 \mathrm{~kb}$ deletion can be identified in $60 \%$ of $\mathrm{FH}$ subjects ${ }^{5}$ and in a Finnish population a $9.5 \mathrm{~kb}$ deletion can be identified in $50 \%$ of $\mathrm{FH}$ patients. In the Munich population, major rearrangements of the LDLR gene are rare (unpublished data) and therefore restriction enzyme mapping is not feasible for diagnosis in most families.

In cases in which unknown point mutations cause FH, diagnosis can be carried out using RFLPs and linkage analysis in family studies. The first polymorphism in the LDLR gene and its use in diagnosis was described in $1985 .{ }^{19}$ Since then at least 10 RFLPs have been described and their applicability has been shown by various authors. In general, the use of RFLPs for diagnosis is determined by their degree of heterogeneity and linkage to other RFLPs. The genotype distribution, the degree of heterogeneity, and the linkage disequilibrium is now known for several polymorphisms in different populations $\mathrm{s}^{761720}$ and a strategy for haplotype analysis of the LDLR gene was recently presented from data from a normal Caucasian American population. ${ }^{9}$ However, less is known about the general applicability of linkage analysis in family studies to diagnose FH. Using linkage analysis with three RFLP haplotypes (PvuII, ApalI, and AvaII) it was possible to identify the haplotype of the affected gene in $\mathbf{5 7}$ 
Table 4 Mean (SE) lipid levels in 97 family members in which diagnosis of $F H$ has been confirmed or excluded using four RFLPs at the LDLR gene locus. Total cholesterol and $L D L$ cholesterol levels are significantly different between $F H$ and normal subjects only.

\begin{tabular}{|c|c|c|c|c|c|c|c|}
\hline Group & Sex & No & Age & Trgl & Chol & LDL & HDL \\
\hline \multicolumn{8}{|c|}{ LDLR defective } \\
\hline & Males & 35 & $34(2 \cdot 6)$ & $152(21 \cdot 0)$ & $326^{*}(13 \cdot 2)$ & $251 \dagger(12 \cdot 5)$ & $44(2 \cdot 2)$ \\
\hline \multicolumn{8}{|c|}{ LDLR normal } \\
\hline & Males & 29 & $28(3.0)$ & $143(28 \cdot 8)$ & $204^{*}(6 \cdot 7)$ & $130 \dagger(4 \cdot 2)$ & $49(2 \cdot 8)$ \\
\hline & Females & 8 & $27(6 \cdot 0)$ & $97(19 \cdot 7)$ & $203 *(10 \cdot 7)$ & $130 \dagger(12 \cdot 6)$ & $54(3 \cdot 1)$ \\
\hline
\end{tabular}

${ }^{*} \mathrm{~F}=78.241, \mathrm{df}=1, \mathrm{p}<0.00001 . \dagger \mathrm{F}=85.981, \mathrm{df}=1, \mathrm{p}<0.00001$.

Italian families and to carry out unequivocal diagnosis in $67 \%$ of the cases. ${ }^{20}$

In our German population, comparison of haplotype distribution showed no striking difference between the normal Caucasian American and normal African population from which comparable data are available. Within our population there is also no striking difference in haplotype distribution between normal and affected genes. Therefore, it is not possible to diagnose $\mathrm{FH}$ by identifying a certain haplotype in our population. This approach has been shown to be useful in an African population only. ${ }^{16}$ However, using linkage analysis with four polymorphisms we were able to identify the affected gene in 31 German FH families and diagnosis of FH was feasible in $72 \%$ of family members. These results are in very good agreement with the estimation from calculations on frequencies and heterozygosities of RFLPs as predicted before. ${ }^{9}$ Comparing data from pedigree analysis with lipid levels, we identified subjects with normal cholesterol levels and defective LDLR genes and subjects with moderate hypercholesterolaemia and normal LDLR genes. It is a well known phenomenon that lipid levels do overlap between subjects with normal and defective LDL receptors, especially in younger

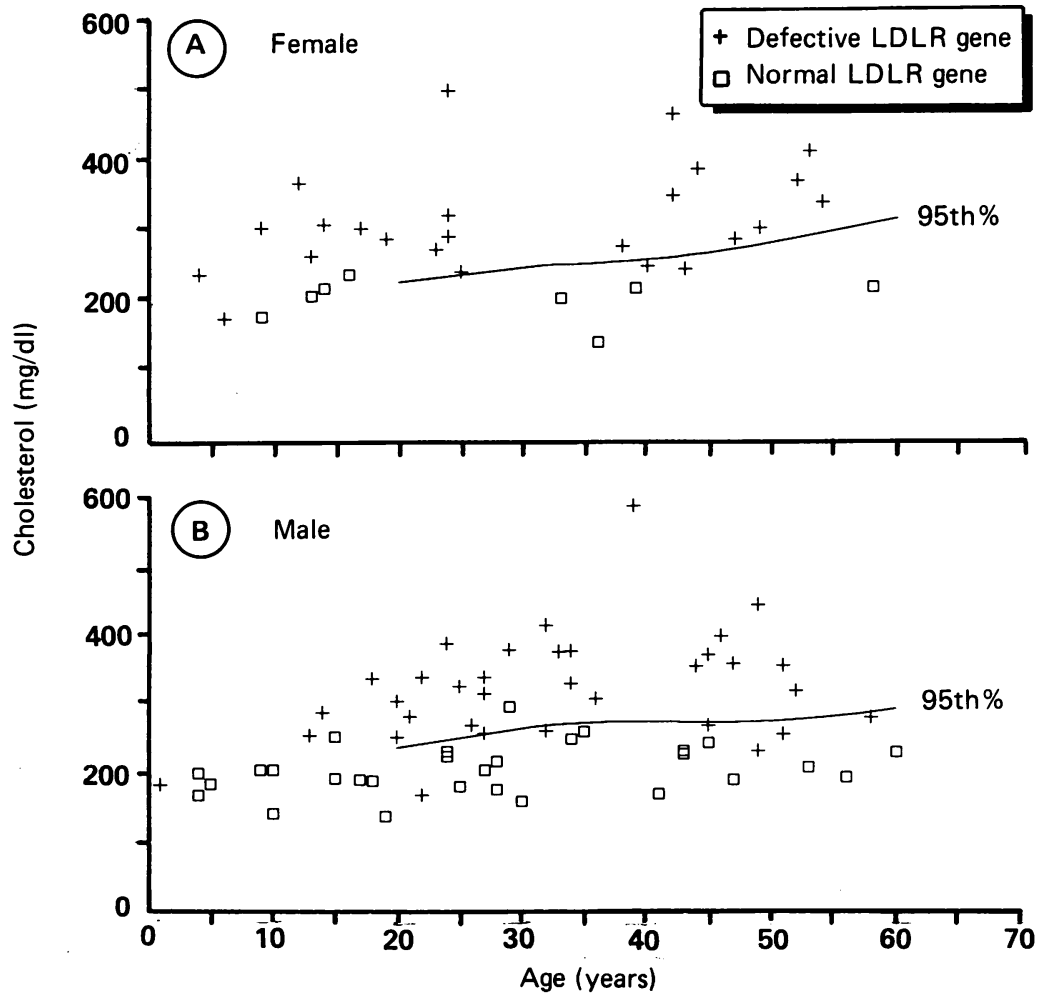

Figure 3 Age dependent cholesterol levels of $(A)$ female and $(B)$ male $F H$ heterozygotes and normal family members in 31 families. 
cases, and even within the same family. Similar results have been shown in patients with $\mathrm{FH}$ confirmed by tissue culture experiments. ${ }^{21}$ Cholesterol levels do not always allow unequivocal diagnosis, especially in children and young adults, since these values may fall in the upper range of normal..$^{22}$ As appropriate diet and specific treatment of patients with $\mathrm{FH}$ can reduce their risk of coronary heart disease, it is advantageous to identify affected subjects before the onset of clinical signs and symptoms.

We would like to thank Steve Humphries for helpful discussion on preparation of this manuscript.

1 Goldstein JL, Brown MS. Familial hypercholesterolemia. In: Stanbury JB, Wyngaarden JB, Fredrickson DS, Goldstein JS, Brown MS, eds. The metabolic basis of inherited disease. New York: McGraw-Hill, 1983:672-712.

2 Goldstein JL, Brown MS. Progress in understanding the LDL receptor and HMG CoA reductase, two membrane proteins that regulate the plasma cholesterol. F Lipid Res 1984; 25:1450-61.

3 Tolleshaug H, Hobgood KK, Brown MS, Goldstein JL. The LDL receptor locus in familial hypercholesterolemia - multiple mutations disrupt transport and processing of a membrane receptor. Cell 1983;32:941-51.

4 Leitersdorf E, Van Der Westhuyzen DR, Coetzee GA, Hobbs HH. Two common low density lipoprotein receptor gene mutations cause familial hypercholesterolemia in Afrikaners. 7 Clin Invest 1989;84:954-61.

5 Hobbs HH, Brown MS, Russell DW, Davignon J, Goldstein JL. Deletion in the gene for the low-density-lipoprotein receptor in a majority of French Canadians with familial hypercholesterolemia. $N$ Engl f Med 1987;317:734-7.

6 Aalto-Setälä K, Helve E, Kovanen PT, Kontula K. Finnish type of low density lipoprotein receptor gene mutation (FHHelsinki) deletes exons encoding the carboxy-terminal part of the receptor and creates an internalization-defective phenotype. $\mathcal{F}$ Clin Invest 1989;84:499-505.

7 Schuster H, Stiefenhofer B, Wolfram G, et al. Four DNA polymorphisms in the LDL-receptor gene and their use in diagnosis of familial hypercholesterolemia. Hum Genet 1989;82:69-72.

8 Hobbs HH, Leitersdorf E, Goldstein JL, Brown MS, Russell DW. Multiple $\mathrm{crm}^{-}$mutations in familial hypercholesterolemia. Evidence for 13 alleles, including four deletions. $f$ Clin Invest 1988;81:909-17.
9 Leitersdorf E, Chakravarti A, Hobbs HH. Polymorphic DNA haplotypes at the LDL receptor locus. Am $\mathcal{f}$ Hum Genet $1989 ; 44: 409-21$

10 Botstein D, White RL, Skolnick WM, Davis RW. Construction of a genetic linkage map in man using restriction fragment length polymorphisms. Am $\mathcal{F}$ Hum Genet 1980;32:314-31.

11 Spengel $F$, Harders-Spengel $\mathrm{K}$, Keller $\mathrm{C}$, Wieczorek A, Wolfram G, Zöllner N. Use of fibroblast culture to diagnose and genotype familial hypercholesterolemia. Ann Nutr Metab 1982;26:240-7.

12 Friedewald WT, Lewy RI, Fredrickson DS. Estimation of plasma low-density-lipoprotein cholesterol concentration without use of the preparative ultracentrifuge. Clin Chem 1972;18:499.

13 Havel R, Eder H, Bragdon J. The distribution and chemical composition of ultacentrifugally separated lipoproteins in human serum. $\mathcal{f}$ Clin Invest 1955;34:1345.

14 Kunkel LM, Smith KD, Boyer SH, et al. Analysis of human Ychromosome-specific reiterated DNA in chromosome variants. Proc Natl Acad Sci USA 1977;74:1245-9.

15 Schuster H, Rauh G, Kormann B, et al. Familial defective apolipoprotein B-100: comparison with familial hypercholesterolemia in 18 cases detected in Munich. Arteriosclerosis 1990;10:577-81.

16 Kotze MJ, Langenhoven E, Retief AE, Seftel HC, Henderson HE, Weich HFH. Haplotypes identified by 10 DNA restriction fragment length polymorphisms at the human low density lipoprotein receptor gene locus. F Med Genet 1989;26:2559.

17 Taylor $R$, Jeenah $M$, Seed $M$, Humphries S. Four DNA polymorphisms in the LDL receptor gene: their genetic relationship and use in the study of variation at the LDL receptor locus. F Med Genet 1988;25:653-9.

18 Henze K, Wallmüller-Strycker A, Bauer M, Barth C, Wolfram G, Zöllner N. Cholesterin und Triglyceride im Serum einer Münchner Bevölkerungsgruppe: Beziehungen zu Alter und Geschlecht. 7 Clin Chem Clin Biochem 1981;19:1013-9.

19 Humphries SE, Kessling AM, Horsthemke B, et al. A common DNA polymorphism of the low density lipoprotein (LDL) receptor gene and its use in diagnosis. Lancet 1985; i:1003-5.

20 Daga A, Mattioni T, Balestreri R, Coviello DA, Corte G, Bertolini S. Use of three DNA polymorphisms of the LDL receptor gene in the diagnosis of familial hypercholesterolemia. Hum Genet 1990;84:412-6.

21 Keller CH, Harders-Spengel $\mathrm{K}$, Spengel F, Wieczorek A Wolfram G, Zöllner N. Serum cholesterol levels in patients with familial hypercholesterolemia confirmed by tissue culture. Atherosclerosis 1981;39:51-9.

22 Leonard JV, Whitelaw AGL, Wolff OH, Lloyd JK, Slack J. Diagnosing familial hypercholesterolemia in children by measuring serum cholesterol. BMf 1977;i:1566-8. 